\title{
NILAI KARAKTER DALAM NOVEL MENCINTAI-NYA SEBELUM MENCINTAIMU KARYA RISKA WATI HARFIN
}

\author{
Rahmat \\ SMP Negeri I Turi \\ Telp.082 232307106 \\ Pos-el bapakrahmat25@gmail.com
}

\begin{abstract}
Abstrak: Tujuan penelitian tesis ini adalah: mendeskripsikan nilai-nilai karakter yang diajarkan oleh Harfin dalam novel Mencintai-Nya sebelum Mencintaimu. Penelitian ini menggunakan metode kualitatif. Metode kualitatif sebagai prosedur penelitian yang menghasilkan data deskriptif berupa kata-kata, frasa, klausa, dan kalimat pada setiap paragraf. Data penelitian berupa sumber data, teknik pengumpulan dan teknik analisis data, dilakukan dengan analisis isi untuk mengungkap 5 nilai karakter yaitu karakter religious, gotong royong, mandiri, nasionalisis dan integritas. Karakter religius adanya tokoh yang bewatak baik (protagonis) dan tokok yang berwatak jelek. Karakter gotong -royong adanya sikap tolong menolong dan saling menasehati. Karakter mandiri biasa hidup serba kekurangan, kerja keras, memiliki motivasi yang lebih tidak tergantung kepada orang lain. Karakter nasionalisme berupa pengabdian guru honorer di sebuah Sekolah Dasar. Karakter intergritas kerja keras dengan keyakinan dan optimis bisa menyelesaikan pekerjaan seraya berdoa kepada-Nya. Karakter yang ditanamkan dapat menjadi acuan pembelajaran di sekolah dalam rangka mewujudkan anak Indonesia yang berkarakter religius, gotong-royong, mandiri, nasionalisme dan integritas.
\end{abstract}

Kata Kunci: karakter, hijrah, jodoh, sukses

Abstract: The purpose of this thesis research is to describe the character values taught by Harfin in the novel Loving Him before Loving You. This study uses a qualitative method. Qualitative method as a research procedure that produces descriptive data in the form of words, phrases, clauses, and sentences for each paragraph. Research data are data sources, collection techniques and data analysis techniques which include data description, data analysis and data conclusions. Data analysis was carried out by content analysis to reveal the 5 character values, namely religious character, mutual cooperation, independence, nationalism and integrity. Religious characters have good characters (protagonists) and person who are ugly. Character of mutual cooperation is the attitude of helping and advising each other. The usual independent character lives in deprivation, hard work, has a motivation that is less dependent on others. Nationalism character in the form of dedication of honorary teachers in an elementary school. The integrity character of hard work with confidence and optimism can complete the work while praying to Him. The character implanted can be a reference for learning in schools in order to realize Indonesian children who are religious, mutual help, independent, nationalism and integrity.

Keywords: character, hijra, soul mate, success 


\section{PENDAHULUAN}

$\begin{array}{ccr}\text { Karya } & \text { sastra } & \begin{array}{r}\text { diciptakan } \\ \text { pengarangnya }\end{array} \\ \text { untuk } & \text { memberikan }\end{array}$ pencerahan kepada para pembaca agar tertanamkan karakter yang disampaikannya. Oleh karena itu, karya sastra itu diciptakan sebagai realisasi kejadian yang ada di dunia imajinatif. Karya sastra ditulis oleh pengarangnya untuk mewakili zamannya. Kepekaan pengarang terhadap lingkungannya bisa dituangkan dalam sebuah karya. Dengan lahirnya karya tersebut, pembaca bisa mempelajari watak-watak tokoh yang ada, mengamalkan amanat dalam kehidupan sehari-hari.

Karya sasta dapat dipandang dari dua arah. Pertama, sastra dipandang sebagai karya yang merupakan rentetan sejarah. Kedua, sastra dipandang secara umum melalui: studi prinsip, kategori, dan kreteria, atau secara khusus telaah langsung terhadap karya sastra. Dalam menilai karya sastra (novel dan drama) seorang kritukus tidak boleh menutup mata ragam karya sastra yang lain. Kebenaran dalam novel diukur dan dibandingkan dengan kebenaran kehidupan yang konkrit (Sariban, 2015: $1-5)$.

Untuk bisa memahami karya yang diciptakan oleh seorang pengarang dapat digunakan pendekatan teoritis yang berkaitan dengan apa yang ada pada novel Mencintai-Nya sebelum mencintaimu karya Riska Wati Harfin. Menurut Ratna ( 2013) pendekatan teoristik berfungsi memberikan perhatian utama terhadap pembaca. Pendekatan teoristis memberikan manfaat yang luas terhadap pembaca untuk menafsirkan apa yang dihasilkan oleh pengarang dan bahkan pembaca seakan-akan mengalahkan si pengarangnya. Pembaca dapat menafsirkan teks-teks yang ditulis pengarang baik implisit maupun eksplinsit. Pada penelitian ini akan dibahas mengenai karakter yang ada pada novel yang menjadi objek penelitian. Pendidikan Penguatan Karakter dilaksanakan dengan menerapkan nilainilai Pancasila dalam pendidikan karakter terutama meliputi nilai-nilai religius, jujur, toleran, disiplin, bekerja keras, kreatif, mandiri, demokratis, rasa ingin tahu, semangat kebangsaan, cinta tanah air, menghargai prestasi, komunikatif, cinta damai, gemar membaca, peduli lingkungan, peduli sosial, dan bertanggungjawab (Perpes Nomor: 87 Tahun 2017).

Riska Wati Harfin novelis muda kelahiran Palopo, Sulawesi Selatan 16 Maret 1994 menginspirasi kepada remaja tentang pergaulan masa kini. Remaja harus berhati-hati dalam bergaul. Jika salah bergaul tentunya bukan diri sendiri yang menanggung akibatnya. Tetapi juga menyangkut keluarga dan bisa lembaga yang disinggahi. Dalam novelnya riska mengatakan bahwa banyak di antara para remaja yang menyesal karena salah pergaulan, berpacaran, bervalentin day, dan berbuat yang tidak dibenarkan oleh agama.

"Melati adalah sosok wanita yang taat, pendiam, dan membatasi pergaulan dengan lawan jenis. Ia seorang mahasiswa yang tekun menghadiri majelis ilmu, ia rajin mempelajari ilmu agama dan melati menjadi salah satu gadis inspirator di dunia akademik. Parasnya menawan, cantik, dan anggun. Ia menjadi primadona dan rebutan para pemuda. Melati tak merespon setiap pemuda yang datang kepadanya.

Rutinitasnya sebagai seorang mahasiswa membuat melati banyak menghabiskan waktu di kampus. Di tengah kesibukan, ia tak menyadari jika ada orang lain yang diam-diam mendekatinya. Usaha pemuda ini berhasil mendapatkan nomor HP. Perlahan ia mengirim SMS kepada melati, awalnya 
ingin belajar ilmu agama. Melati senang mengetahui maksud pemuda tersebut dan bersedia berbagi ilmu. Hari-hari semakin akrab, si pemuda merasa bahagia karena modus yang dilakukan membuahkan hasil. Hingga suatu hari si pemuda minta tolong kepada Melati untuk berkunjung ke rumahnya menemani sang bunda yang sedang sendirian. Tanpa pikir panjang apa lagi menyimpan kecurigaan, melati bergegas menuju kediamanan pemuda tersebut.

Berbicara perkara jodoh, semua manusia pasti menginginkan yang terbaik terutama dari sisi agama. Tak ada manusia yang ingin salah dalam memilih jodoh. Semua usaha pasti akan dikerahkan untuk mendapatkan sosok yang terbaik. Karena sebuah pernikahan bukan tentang siapa yang cepat, tetapi tentang siapa yang tepat dan datang pada waktu yang tepat. Namun, perlu diperhatikan apakah usaha yang mendapat sosok yang terbaik, murni karena Allah atau hanya justru sekedar ingin mencintai saja tanpa ada unsur ibadah di dalamnya.

Sebab memilih sosok yang akan mendampingi kita nantinya, sangat besar perannya kelak dalam kehidupan dunia ini maupun kelak di akhirat. Pernikahan yang terjalin hanya berlangsung selama dua atau satu hari saja, tetapi akan berlangsung sampai ke jannah-Nya. Tak dapat dipungkiri, banyak orang yang akhirnya salah dalam memilih pasangan, sebab melupakan hal-hal yang menjadi prinsip dalam memilih seorang pasangan hidup.

Bahkan di zaman sekarang,
sebagian lebih memilih menjalin
hubungan yang diawali dengan pacaran.
Tak ada batas yang membatasi untuk
berdua-duaan dan bermesra-mesraan.
Sehingga timbul hasrat dan hawa nafsu

yang tak terkendali. Inilah yang menjadi cikal bakal merosotnya iman seseorang. Mengharap yang terbaik tetatpi tidak bisa membuat dirinya menjadi yang terbaik. Dalam hal ini perempuanlah pihak yang dirugikan (Harfin, 2018: 203-204).

Wanita adalah tiang negera. Jika ingin menegakkan sebuah negara maka lindungilah wanita. Sebaliknya jika ingin merobohkan negara maka hinakan mereka. Baik dan tidaknya rumah tangga atau negara bergantun peran dari wanita. Wanita mempunyai peran strategis dan penting dalam membina rumah tangga demi tegaknya suatu masyarakat dan negara yang diridhoi Allah SWT.

Tujuan penelitian ini adalah mendiskripsikan Nilai karakter yang di ajarkan pada Novel Mencintai-Nya sebelum Mencintaimu .karya Riska Wati Harfin berikut:

1) Mendeskripsikan nilai karakter religius yang diajarkan dalam novel Mencintai-Nya sebelum Mencintaimu karya Riska Wati Harfin ;

2) Mendeskripsikan nilai karakter gotong-royong yang diajarkan dalam novel Mencintai-Nya sebelum Mencintaimu karya Riska Wati Harfin ;

3) Mendeskripsikan nilai karakter mandiri yang diajarkan dalam novel Mencintai-Nya sebelum Mencintaimu karya Riska Wati Harfin ;

4) Mendeskripsikan nilai karakter nasionalis yang diajarkan dalam novel Mencintai-Nya sebelum Mencintaimu karya Riska Wati Harfin ;

5) Mendeskripsikan nilai karakter integritas yang diajarkan dalam novel Mencintai-Nya sebelum 
Mencintaimu karya Riska Wati Harfin ;

\section{METODE PENELITIAN}

Penelitian ini tergolong penelitian kualitatif. Penelitian kualitatif sebagai prosedur penelitian yang menghasilkan data deskriptif berupa kata-kata, frasa, klausa, dan kalimat pada setiap paragraf dalam novel Mencintai-Nya sebelum Mencintaimu karya Riska Wati Harfin. Penelitian kualitatif memberikan perhatian terhadap data alamiah, data dalam hubungannya dengan konteks keberadaannya. Dalam penelitian sastra, misalnya, akan dilibatkan pengarang, lingkungan sosial di mana pengarang berada, termasuk unsur-unsur kebudayaan pada umunya.

Sumber data penelitian tesis ini yang utama adalah novel Mencintai-Nya sebelum Mencintaimu karya Riska Wati Harfin yang diterbitkan Araska Publisher Yogyakarta, cetakan pertama, Februari 2018, tebal 240 halaman. Dalam penelitian sastra sumber datanya dapat berupa masyarakat sebab masyarakatlah yang menghasilkan karya sastra tersebut.

Teknik pengumpulan data merupakan langkah yang paling utama dalam teknik penelitian, karena tujuan utama dari penelitian adalah mendapatkan data. Teknik pengumpulan data pada penelitian ini dilakukan dengan simak dan catat. Difinisi simak adalah memperhatikan dengan baik -baik apa yang dibaca orang. Catat adalah menuliskan dari apa yang telah dibaca. Dalam penelitian kualitatif, pengumpulan data dilakukan pada natural setting (kondisi yang alamiah), sumber data primer dan teknik pengumpulan data lebih banyak observasi, wawacara, dan dokumentasi (Sugiyono, 2013: 309)

Analisis data penelitian kualitatif dilakukan sejak sebelum memasuki lapangan, selama di lapangan, dan setelah selesai di lapangan. Analisis data menjadi pegangan bagi penelitian selanjutnya. Analisis data dalam penelitian kualitatif lebih difokuskan selama proses di lapangan bersamaan dengan pengumpulan data.

Penyimpulan dilakukan setelah proses analisis selesai yang menggambarkan ditemukanya bentukbentuk nilai karakter yang meliputi :Temuan nilai karakter Religius,nilai karakter gotong royong,nilai karakter mandiri,nilai karakter nasionalisme dan nilai karakter intergritas .

\section{HASIL DAN PEMBAHASAN}

Pada Novel Mencintai-Nya sebelum Mencintaimu karya Riska Wati Harfin terdapat nilai Karakter sebagai berikut :

Nilai Karakter Religius, hubungan individu dengan Tuhan, individu dengan sesama dan individu dengan lingkungan. Dalam nilai karakter Religius terdapat nilai karakter tokoh berwatak baik dan tokoh berwatak jelek. Pada novel ini ditemukan nilai karakter yang baik yaitu jujur, kesabaran, rajin berdoa, istiqomah, giat belajar/ ikhtiar, melakukan pernikahan, khusnudhon, berbakti kepada orang tua, gemar bersedekah, dan menyesal setelah berbuat dosa atau maksiat. Nilai karakter yang jelek yaitu bohong/ dusta, cinta dunia, berbuat maksiat dan zina.

Hasil penelitian terdahulu nilai pendidikan karakter religius merupakan nilai karakter yang meliputi ideologi, peribadatan, penghayatan, pengetahuan, dan pengamalan.Nilai pendidikan karakter tanggung jawab merupakan perwujudan nilai pendidikan karakter religius. ada dua jenis nilai moral, yaitu moral baik dan moral buruk. Moral baik meliputi; sosial, akhlak dan etika, taat beribadah, rajin belajar dan bekerja, mampu mengendalikan diri, dan penyesalan. Nilai moral buruk meliputi; 
intrik, konflik, dan bohong. Pendidikan karakter religius diwujudkan dalam bentuk tanggung jawab yang meliputi; tanggung jawab kepada Allah swt, tanggung jawab terhadap diri sendiri, keluarga, masyarakat, bangsa dan negara. Tanggung jawab adalah ciri manusia beradab (berbudaya). Manusia merasa bertanggung jawab karena ia menyadari akibat baik atau buruk perbuatannya itu, dan menyadari pula bahwa pihak lain memerlukan mengabdian atau pengorbanannya.

Nilai karakter Gotong-Royong, manusia adalah sebagai makhluk sosial, artinya ia tidak bisa memenuhi kebutuhan sendiri, melainkan membutuhkan orang lain. Oleh karena itu perlu dikembangkan sikap tolong-menolong atau gotong royong. Mulai lahir manusia membutuhkan bantuan orang lain untuk bisa hidup. Membutuhkan bantuan orang tua, bidan/dukun beranak, dan pengasuh. Anak merupakan amanat Allah SWT yang harus dirawat dan didik untuk menjadi insan yang beriman dan bertaqwa supaya kelak bisa membahagiakan orang tua baik di dunia dan akhirat. Jika anak dibekali dengan pendidikan agama tentu sejak kecil maka di usia dewasa akan tertanamkan karakter-karakter yang positif. Tetapi juga sebaliknya jika anak tidak dibekali karakter yang baik sejak dini tentu anak dan orang tua sendiri yang akan merasakan kerugian. Oleh karena itu, sebagai insan sosial, perlu ditanamkan kegotong-royongan untuk mencapai tujuan pribadi maupun bersama. Tindakan menghargai semangat kerja sama dan bahu membahu menyelesaikan persolan bersama, menjalin komunikasi dan persahabatan, memberi bantuan/ pertolongan pada orang-orang yang membutuhkan. Sikap gotong royong dijiwai oleh perasaan senasib. Sikap ini mencermenkan sila ke tiga Pancasila. Dalam agama manusia sebagai anggota diperbolehkan tolong menolong dalam kebaikan dan taqwa dan dilarang tolong menolong dalam hal keburukan dan kejahatan.Dengan demikian nilai gotong royong yang ditemukan dalam dalam Novel ini adalah tolong menolong dan saling menasehati .

Nilai karakter Mandiri, kemandirian hidup mengajarkan manusia untuk lebih dewasa dalam negarungi hidup dan kehidupan. Kemandirian hidup bisa didapatkan seseorang melalui pengalaman dan perjalanan hidup. Seseorang yang biasa hidup serba kekurangan, biasanya memiliki motivasi yang lebih dibandingkan dengan mereka yang hidup serba ada. Orang yang serba ada biasanya bergantung kepada pihak lain. Apakah itu orang tua atau pihak lain. Sedangkan orang yang kekurangan seperti tokoh Afif yang berasal dari keluarga tidak mampu, ia nekat bekerja keras bersama dengan teman untuk memenuhi hajat hidup dan untuk mempersunting calon istrinya. Ia rela bekerja dan belajar demi masa depan yang gemilang. Kerja keras Afif membuahkan hasil, ia menikah dengan seorang gadis yang lebih tua darinya. Tetapi, perbedaan usia tidak menjadikan masalah bagi keduanya untuk mengarungi bahtera rumah tangga. Yang terpenting baginya ada saling keberterimaan. Membangun rumah tangga yang terpenting didasari dengan niat karena Allah dan untuk memperoleh keturunan yang sah. Suka dan duka mereka jalani berdua walaupun hidup di rumah kontrakan. Sikap dan perilaku tidak bergantung kepada orang lain dan menggunakan segala kemampuan, pikiran, dan waktu untuk mencapai cita- 
cita. Untuk bisa mandiri, seseorang harus bekerja keras, tangguh tahan banting, mempunyai daya juang tinggi, tidak banyak mengeluh, profesional, kreatif, dan mempunyai semangat menjadi pembelajar sepanjang hayat.Dengan demikian nilai Mandiri yang ditemukan dalam Novel ini adalah biasa hidup serba kekurangan, kerja keras, memiliki motivasi yang lebih dan tidak tergantung kepada orang lain.

Nilai karakter Nasionalisme, Nasionalisme dibangun dari keluarga, jika keluarga harmonis maka negara juga aman damai dan sejahtera. Nasionalisme dibangun melalui keluarga yang diikat dengan sah oleh undang-undang perkawinan Nomor 1 tahun 1974 menyatakan bahwa perkawinan ialah ikatan lahir bathin antara seorang pria dengan seorang wanita sebagai suami isteri dengan tujuan membentuk keluarga (rumah tangga) yang bahagia dan kekal berdasarkan ketuhanan Yang Maha Esa. Cara berpikir, bersikap, dan berbuat yang menunjukkan kesetiaan, kepedulian, dan penghargaan yang tinggi terhadap bahasa, lingkungan fisik, sosial, budaya, ekonomi dan politik bangsa dan negara di atas kepentingan diri dan kelompok.Dengan demikian nilai Nasionalisme yang ditemukan dalam novel ini adalah pengabdian guru honorer di sebuah Sekolah Dasar, selalu meningkatkan dan mengembangkan empat kompetensi Guru yaitu pedagogic, kepribadian, sosial dan professional.

Nilai karakter Integritas, Integritas adalah keadaan yang menunjukkan kesatuan yang utuh sehingga mempunyai potensi dan kemampuan yang memancarkan kewibawaan dan kejujuran. Seseorang bisa menjadi dewasa manakala sudah teruji oleh pengalaman hidup. Mereka sudah tangguh dalam menghadapi berbagai cobaan dan terpaan kehidupan. Sudah banyak makan asam garam pahitnya kehidupan. Allah memberikan ujian agar manusia hati-hati dan waspada dalam mengarungi bahtera kehidupan. Peran seorang ibu harus mendidik anaknya dengan akhlak yang terpuji dan mencegahnya dari perbuatan yang tidak baik, seperti berdusta, mencuri, mencela, dan sebagainya. Orang tualah yang memegang peranan penting dalam mencetak karakter anak dikemudian hari kelak. Jika anak dibiasakan dengan pekerjaan yang baik dan terpuji, misalkan mengucapkan salam setiap ketemu orang atau bepergian dan seterusnya, maka mereka akan terbiasa mengucapkannya. Setiap manusia bisa mengapai impiannya dengan kerja keras dan diikuti dengan keyakinan dan selalu berharap dengan ridha Allah SWT. Diceritakan bahwa, sang pelaku bisa membuat orang tuanya bahagia terhadap usaha yang telah dilakukan. Dalam waktu yang singkat sang pelaku dapat menyelesaikan ujian akhir dan ujian skripsi. Keberhasilan itu semua karena sang pelaku optimis dapat menyelesaikan semua pekerjaan dan seraya berdoa kepada-Nya. Perilaku yang didasarkan pada upaya menjadikan dirinya sebagai orang yang dapat dipercaya dalam perkataan, tindakan, dan pekerjaan. Sikap tanggung jawab sebagai warga negara, aktif terlibat dalam kehidupan sosial.Dengan demikian nilai intergritas yang ditemukan dalam novel ini adalah rela menanti jodoh dari Allah tanpa pacaran, menjaga diri dari hal-hal yang maksiat, kerja keras dengan keyakinan dan optimis bisa menyelesaikan pekerjaan seraya berdoa kepada-Nya .

\section{SIMPULAN DAN SARAN}

Berdasarkan hasil penelitian yang diperoleh, ada lima Nilai karakter yang dapat peneliti simpulkan dalam Novel 
Mencinta-Nya sebelum Mencintaimu karya Riska Wati Harfin sebagai berikut.

Nilai Karakter Religius, nilai yang mengajarkan kebaikan dan kejelekan. Gotong-royong, sebagai manusia sosial tidak bisa berdiri sendiri dalam memenuhi kebutuhan hidupnya maka dikembangkan sikap saling tolongmenolong, nasehat menasehati dalam kebajikan dan melarang berbuat yang dilarang oleh agama. Mandiri, kemandirian tokoh dalam mengapai kesuksesan karena rajin belajar, giat bekerja dan berdoa pada akhirnya sang tokoh diberikan kesuksesan dan jodoh yang sesuai dengan harapannya.

Nasionalisme yang diawali dengan membangun rumah tangga yang mawadah warohmah maka akan terbentuk pemimpin bangsa yang cerdas, tangguh, disiplin, dan bertanggung jawab.

Intergitas nilai yang mencerminkan keutuhan dan kemantapan sikap seseorang dalam menghadapi cobaan dan terpaan serta liku-liku hidup sang tokoh dalam mengapai jodoh yang dinantikan yang bisa dilihat dalam kehidupan nyata sehari-hari.

Berdasarkan hasil penelitian ini penulis mengajukan saran kepada Pengarang, bahasa yang digunakan kurang familier sehingga para pembaca kesulitan dalam memahami dan menangkap amanat dari pengarang. Bagi pembaca, untuk bisa memahami novel ini dengan benar, maka harus dibaca berulang-ulang dan mengkaitkan unsur ekstrinsik.Karakter yang ditanamkan dapat menjadi acuan pembelajaran di sekolah dalam rangka mewujudkan anak Indonesia yang berkarakter religius, gotong-royong, mandiri, nasionalisme dan integritas.

\section{DAFTAR PUSTAKA}

Abdullah, M. Yatimi. 2008. Studi Akhlak dalam Perspektif Alquran. Jakarta: Amzah.

As-Subki, Ali Yusuf. 2010. Fiqih Keluarga Pedoman Berkeluarga dalam Islam. Jakarta: Amzah.

Ath-Tharsyah, Syaikh Adnan. 2004. Menjadi Wanita Sukses dan Dicintai. Penerjemah Abdul Ghofar EM. Jakarta: Pustaka Al-Kausar.

Azzam, Abdul Aziz Muhammad dan Abdul Wahhab Sayyed Hawwas. 2011. Fiqh Munakahat Khitbah, Nikah, dan Talak. Jakarta: Amzah.

Depag. 2008. Alquran dan Terjemahnya. Jakarta: Yayasan Penyelenggaran Penterjemah/ Pentafsir Alquran.

Harfin, Riska Wati. 2018. Mencinta-Nya sebelum Mencintaimu. Yogyakarta: Ariska Publisher.

Mulyasa. E. 2013. Manajemen Pendidikan Karakter. Jakarta: Bumi Aksara.

Nifan, Khoirun. 2015. Nilai-Nilai Pendidikan Karakter Religius dalam Novel-Novel Karya Tere Liye. Malang: Universitas Negeri Malang.

Ratna, Nyoman Kutha. 2013. Teori,Metode dan Teknik Penilitian Sastra. Yogyakarta: Pustaka Pelajar.

Saleh, Akh. Muwafik. 2011. Membangun Karakter dengan Hati Nurani Pendidikan Karakter untuk Generasi Bangsa. Jakarta: Erlangga.

Sariban. 2015. Penelitian Sastra Teori dan Penerapan. Surabaya: Lentera Cendekia. 
